\title{
Functional electrical stimulation therapies after spinal cord injury
}

\author{
David R. Gater, Jr. ${ }^{\mathrm{a}, \mathrm{b}, *}$, David Dolbow ${ }^{\mathrm{a}}$, Britney Tsui ${ }^{\mathrm{b}}$ and Ashraf S. Gorgey ${ }^{\mathrm{a}, \mathrm{b}}$ \\ a Spinal Cord Injuries and Disorders, Hunter Holmes McGuire VAMC, Richmond, VA, USA \\ ${ }^{\mathrm{b}}$ Virginia Commonwealth University, Physical Medicine and Rehabilitation, Richmond, VA, USA
}

\section{Historical perspective}

The use of electricity for therapeutic purposes dates back to $15 \mathrm{AD}$, when Scribonius Largus, a court physician to the Roman emperor Claudius began using electric shocks from the torpedo ray fish to treat gout pain and headaches [1]. Although the phenomenon of electricity had been used for centuries the actual word "electricity" was not in use until the 1600's, when William Gilbert, an English physician, coined the new Latin word "electricus" meaning like amber. The Creek word amber refers to the property of attracting small objects after being rubbed [2].

In 1780, Luigi Galvani, an Italian physician and physicist showed that impulses from nerve cells pass to muscles by demonstrating the electrical stimulation of a frog's leg muscles [3]. Italian physicist and nephew of Luigi Galvani, Giovanni Aldini, carried on the work of his uncle by demonstrating the ability to stimulate brain tissue by applying electrical stimulation to the heads of decapitated prisoners [4]. In 1874, physician Robert Bartholow, stimulated muscle contractions while working on the cancerous brain of a live woman [5].

Research into the uses of electricity continued through the 19th and 20th centuries allowing the development of numerous inventions i.e. galvanometer, micro-electrodes, cathode ray oscilloscope, pacemakers and defibrillators [6,7]. These and other advances

*Corresponding author: David R. Gater, Jr., MD, PhD, MS, Chief, Spinal Cord Injuries and Disabilities, Hunter Holmes McGuire VAMC, 1200 Broad Rock Blvd, Richmond, VA 23249, USA. Tel.: +1 804675 5000; E-mail: David.gater@va.gov. have led to the understanding of the structures and functions of the central and peripheral nervous systems, and excitable tissues i.e. neurons, skeletal muscle, cardiac muscle, smooth muscle. These events have made it possible to use electricity to treat a wide variety of disorders including cardiac dysrhythmia, respiratory insufficiency and paralyzed skeletal muscles.

For persons with spinal cord injury (SCI), functional electrical stimulation (FES) is used for cardiac and diaphragmatic pacing, pain management, truncal stability and to improve bone and muscle health, as well as restore or prevent the loss of function. Lasting improvement in function is in high demand since SCI typically occurs in young adults and leads to a large financial burden which increases with the degree of injury. In the first year of injury (in 2009 dollars), persons with low tetraplegia (C5-C8) spend $\$ 535,877$ and persons with high tetraplegia (C1-C4) spend as much as $\$ 829,843$ [8]. Cost-effective utilization of FES may benefit individual consumers and health care systems alike.

Although FES cannot reverse the neurological loss incurred from SCI, it can help to convert Type II muscle fibers back to Type I fibers following the loss of Type I fibers resulting from inactivity [9]. Studies in rodents have shown the necessity of FES for generating movement in paralyzed limbs, rather than passive action alone, in order to acquire sensorimotor improvements [10]. Passive movement did not generate the cortical reorganization necessary to cause lasting changes. Currently, various FES program designs are being studied to determine which provides the greatest aid in SCI rehabilitation efforts. 
The goal of this review is to summarize the available scientific evidence on the efficacy of functional electrical stimulation in areas related to neurorehabilitaion in SCI with special focus on cardiac/respiratory pacing, truncal control and pain management in individuals with neurological insult, as well as rehabilitation and functional restoration of the upper and lower extremities. Finally, a brief discussion of FES for bowel, bladder and sexual function will be provided.

\section{Cardiac pacing}

There are approximately 3 million people worldwide with cardiac pacemakers. Pacemakers are implanted to treat heart rate irregularities, e.g., bradycardia or cardiac conduction block. Although, the great majority of recipients are over age sixty years, pacemakers are used for people of all ages [11], including those with pronounced sympathetic blunting and bradyarrhythmias due to SCI [12].

Taking advantage of the early experimentation with electrical stimulation, cardiac electrostimulation was developed in the mid-eighteenth century with currents from the Leyden jar or Voltaic Pile [13]. These were early forms of batteries which produce electricity from a number of disks that alternate between two different metals separated by acid-moistened pads. Charles Kite describes what may be the first documented electrostimulation resuscitation in his manuscript "An essay upon the recovery of the apparently dead" (London, 1788) [14]. Electrical shocks were transmitted into the thorax of a three year old child that was presumed dead after falling out of a window. The child regained consciousness and after several days returned to full health [14].

Early experimentation with cardiac electrostimulation was largely unaccepted by the medical community and harshly criticized as interfering with natural events. As such, Dr. Mark C. Lidwell, the Australian anesthesiologist and inventor of the first artificial pacemaker in 1926, did not patent his invention and chose to remain anonymous to avoid the scrutiny of the public [15].

In 1930, Albert S. Hyman, a New York cardiologist developed a mechanical cardiac pacing device and popularized the device as a way to restart arrested hearts; he did not distinguish between cardiac arrest and ventricular defibrillation. Along with his brother, an electrical engineer, they built and patented the device that operated by hand crank and spring motor which turned a magnet to supply the electricity to the heart. A short time later, Hyman developed a machine for controlling repetitive electrostimulation of the heart and named the device the "artificial cardiac pacemaker" [7]. Also, in the early 1900's MacWilliam was experimenting with electrical stimulation in managing ventricular dysrhythmia. The work by MacWilliam showed that applications of electrical shock through electrodes, placed on the costal cage, could restore normal heart beats in animals [16].

In 1949 physicians Wilfred Bigelow and John Callaghan teamed up with John Hopps an engineer, to design the first catheter electrode for cardiac stimulation. This device was introduced through the right external jugular vein while a vacuum tube operated external pacing of the atrium [7]. In 1950 Paul Zoll, a Boston surgeon, developed the Zoll Pacemaker which was designed to be less invasive and introduced the technique for pacing the heart through the intact chest wall during asystole [17]. In 1958, Furman and Robinson showed that the heart could be stimulated by connecting an intra-cardiac catheter to a stimulator [18]. Applications of electrical stimulation had then extended to include those with premature and ventricular tachycardia. Using the advancement in the technology of electrical stimulation, the pacemaker was developed to provide a fixed ventricular rhythm in individuals with bradycardia. Over the decades, electric cardiac pacing has evolved into a procedure that provides precise cardiac rhythm and accurate diagnostics to diseased hearts through implantable pacing generators that are small, complex, and durable $[13,19]$, and is certainly indicated for certain individuals with SCI due to their autonomic dysfunction $[12,20]$.

\section{Phrenic nerve versus diaphragmatic pacing}

Most persons with cervical and thoracic SCI experience respiratory insufficiency due to intercostal and abdominal muscle paralysis. Since the phrenic nerves arise from bilateral $\mathrm{C} 3, \mathrm{C} 4$ and $\mathrm{C} 5$ nerve roots, diaphragmatic function is also compromised in those persons with SCI above $\mathrm{C} 4$, often necessitating passive mechanical ventilation. FES can be applied 4-6 months after SCI in persons with intact C3, C4, and C5 lower motor neurons, viable phrenic nerves, healthy lungs, and good sitting tolerance [9]. Previously, FES administration was relegated to direct stimulation of the phrenic nerve (See Fig. 1), however, recent advances in minimally invasive surgery have facilitated electrode 
placement beneath the diaphragm with similar efficacy but less likelihood for complications [21].

Unilateral phrenic nerve stimulation dates back to 1948 when Sarnoff and colleagues reported using a Grass stimulator in a series of case studies [22]. Stimulation of a single phrenic nerve was problematic due to the inefficient, paradoxical motion of the contralateral unpaced hemidiaphragm. Glenn and associates first reported bilateral phrenic nerve stimulation with an implantable system in 1966 [23]. The surgery involved placement of electrodes on the phrenic nerve in the neck and thorax byway of a thoracotomy, with risks including phrenic nerve injury during surgery, pneumothorax and hypoventilation [24]. In the 1980s protocols were changed to utilize uninterrupted simultaneous pacing of both hemidiaphragms, improving minute volumes and better air mixing [24]. As surgical techniques improved, commercial phrenic pacemaker systems were developed, and Medicare reimbursement was provided, such that well over 1000 units had been placed by the mid-1990s [25]. Benefits over passive mechanical ventilation include barotrauma reduction, tracheostomy decannulation, improved vocalization, olfaction, taste, and improved mobility, whereas disadvantages include the initial risks associated with the thoracic surgery, as well as the potential for infection or damage of the implanted leads/electrodes, and possible electrical failure of the system itself [26-28].

The transition from electric stimulation of the phrenic nerves to direct stimulation of the muscular diaphragm signified a less invasive method for diaphragmatic pacing [29]. This procedure has evolved into a much simpler day surgery through laparoscopic placement of intramuscular diaphragmatic electrodes and a home-based ventilator weaning/conditioning program [21]. It has been demonstrated that approximately $40 \%$ of individuals with tetraplegia are able to be supported fulltime by these devices although most patients with diaphragmatic pacemakers continue to have tracheostomies and mechanical ventilators as a back-up to their pacemakers. It is important to note that diaphragmatic pacemakers only improve inspiratory function and do not enhance expiratory functions such as coughing and clearing secretions [30].

\section{Pain management}

Pain is traditionally separated into two main categories, acute (when tissue damage is impending or after injury has occurred) and chronic (pain lasting for

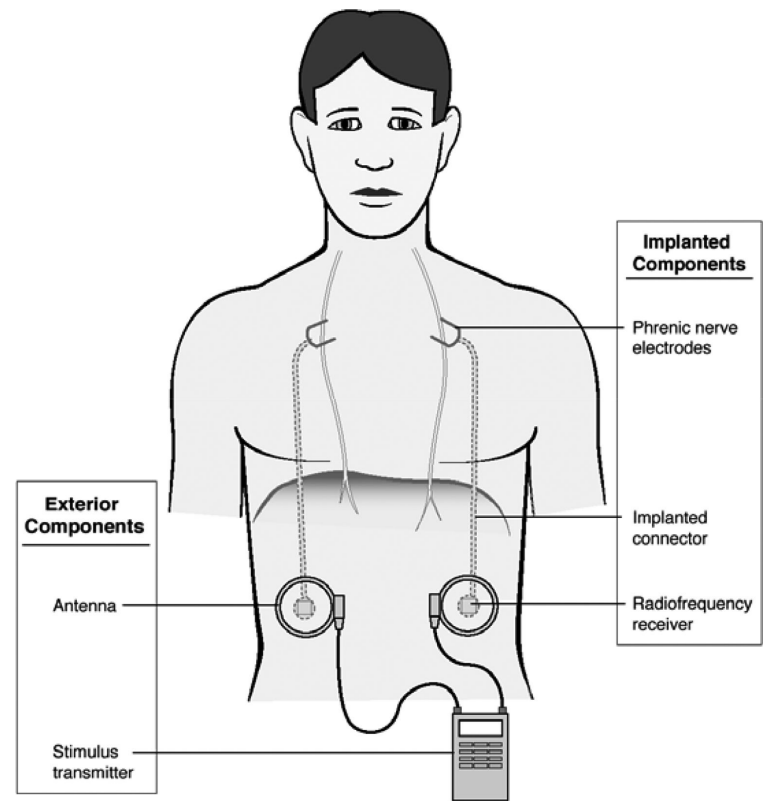

Fig. 1. Functional electrical stimulation of the diaphragm for respiration.

6 months or greater) [31]. Pain after SCI is often further separated into as many as five classifications, (central pain, musculoskeletal pain, visceral pain, neuropathic pain, and psychogenic pain). However, a Task Force on Pain following Spinal Cord Injury of the International Association for the Study of Pain (IASP) introduced a three tiered structure with each tier defining the affected structure and pathology responsible for the pain. The first tier divides pain after SCI into two broad categories, nociceptive and neurpathic pain. Nociceptic pain manifests as dull, aching, and cramping in regions of sensory preservation while neuropathic pain is manifested as sharp, shooting, electric, or burning symptoms occurring in a region of sensory disturbance [32]. In tier two nociceptive pain is further divided into musculoskeletal pain and visceral pain while neuropathic pain is divided into above-level, at level, and below-level of injury. Tier 3 finalizes the divisions into specific structures and pathology of the various pains (Table 1).

Pain is a significant problem for individuals with SCI and may develop during the acute or chronic stages and persist indefinitely [33]. On average, 69\% of patients with SCI experience chronic pain and approximately $33 \%$ report their pain as severe [34]. There are different forms of electrical stimulation, however, that have evolved for functional management of pain at different anatomical regions including Transcutaneous Electrical Nerve Stimulation (TENS), Interferential Current and High Voltage Galvanic Stimulation. The mode of 
Table 1

Three Tiered pain classification after SCI

\begin{tabular}{lll}
\hline Broad type (Tier 1) & Broad system (Tier 2) & Specific (Tier 3) structures/pathology \\
\hline Nociceptive & Musculoskeletal & $\begin{array}{l}\text { Bone, joint, muscle trauma or inflammation. Mechanical instability. Mus- } \\
\text { cle spasm. Secondary overuse syndromes. } \\
\end{array}$ \\
& Visceral & Renal calculus, bowel, sphincter dysfunction, etc. Dysreflexic headache. \\
Above level & Compressive mononeuropathies. Complex regional pain syndromes. \\
At level & Nerve root compression (including cauda equine). Syringomyelia. Spinal \\
& & $\begin{array}{l}\text { cord trauma/ischemia (translational zone etc). Dual level cord and root } \\
\text { trauma (double lesion syndrome). } \\
\text { Spinal cord trauma/ischemia (central dysesthesia syndrome, etc.) }\end{array}$ \\
& Below level &
\end{tabular}

stimulation can be via the spinal cord (electrodes implanted in the epidural space) or via stimulation of the afferent nerves through surface electrodes. TENS is a commonly used noninvasive adjunctive agent in the treatment of musculoskeletal pain and nociceptive pain after SCI [35]. TENS is provided by a small, portable, battery-powered electrical stimulation unit that introduces electrical impulse through surface electrodes. The exact mechanism by which TENS and other forms of electrical stimulation reduces or eliminates pain to improve functional activity is not entirely understood, however there are three main theories that are the basis for the pain reduction phenomenon [36].

The gate control theory of pain developed by Melzack and Wall in 1965 states that pain impulses arrive at a gate, which is believed to be the substantia gelatinosa in the dorsal horn of the spinal cord. When the gate is open pain impulses can pass through and reach the brain allowing recognition of pain. When the gate is partially open only some pain impulses can pass through and when the gate is closed pain impulses are inhibited from passing through to the brain thus pain remains unrealized [37]. It is suggested that the position of the gate depends upon the degree of large (non-painful) or small (painful) nerve fiber firing. When faster large fibers are stimulated by the TENS unit the gate closes so that no impulses can pass through, thus eliminating or reducing pain. Conversely, when small nerve fibers predominate, the pain message can be transmitted [36, 38].

The central biasing theory or central control trigger theory is basically a modification of the gate control theory. Electrical stimulation at peripheral sites trigger the descending of central inhibitory mechanisms, which modulate pain transmission in the dorsal horn of the spinal cord, essentially closing the gate to pain messages [36,38].

The opiate pain control theory is the electrical stimulation of sensory nerve in order to release enkephalin from local sites throughout the central nervous system causing the release of $\beta$-endorphin from the pituitary gland into the spinal fluid $[36,38] \beta$-endorphin is an endogenous opioid peptide transmitter found in both the central and peripheral nervous systems [39].

Shoulder pain is common and at times disabling among those with SCI. During acute SCI, for those with tetraplegia, pain may be caused by impaired function of the shoulder girdle due to limited musculature available to allow proper mechanics of the joint. This results in excessive stress to the joint and soft tissue surrounding the joint [40]. Nerve root impingement is also a consideration with reduced stability in the joint [33]. Chronic shoulder pain is a prevalent problem with between $30 \%$ and $50 \%$ of people with paraplegia reporting chronic shoulder pain [41]. When essentially half or more of the muscular system is eliminated from assisting with activities of daily life, more burden is placed on the remaining muscles and joints. The repetitive and exclusive use of upper extremities for self care, weightrelief, transfers, and wheelchair mobility commonly precipitates overuse pain of the shoulders [42]. Although research reports are mixed, many have found that TENS is helpful in treating chronic shoulder pain after SCI [42-44].

\section{Skeletal muscle applications}

Stimulation of muscles by means of electricity is typically referred to as neuromuscular electrical stimulation (NMS) or functional electrical stimulation (FES). FES has a long history dating back to Luigi Galvani's experimentation on the leg muscles of frogs in 1780 and Robert Bartholow's precipitation of muscular contractions while working on the cancerous brain of a live woman in 1874 [5]. In the mid eighteen hundreds, Guillaume-Benjamin Duchenne, a physician and scientist best known for his discovery of the muscle disease "Duchenne Muscular Dystrophy", experimented with the use of electrical shocks beneath the skin to stimulate facial muscle contractions. Duchenne went on to develop a non-invasive technique of muscle stimulation 
using electrical stimulation on the surface of the skin called "electrisation localisee" [5].

Although utilized for decades, the concept of using electricity to stimulate muscle contractions was not popularized until Soviet sports scientists began using high intensity electrical stimulation to increase muscle force of elite athletes beginning in the 1960's [45]. Since that time the therapeutic uses of FES on skeletal muscle have become more common and varied i.e. muscle reeducation, muscle pump contractions, retardation of muscle atrophy, muscle strengthening, and increasing range of motion [36].

FES selectively activates motor units, which are comprised of an alpha motor neuron and all of the skeletal muscle fibers it innervates. There are three major categories of motor units based on contraction speed and fatigability. Slow (S) or Type I motor units (MU) have small diameter axons and muscle fibers that have a relatively slow speed of contraction and low force output, but are fatigue resistant due to high concentration of oxidative enzymes. Fast fatigable (FF or FG) or Type IIb MU have large diameter axons and muscle fibers with large cross sectional area (CSA) that have fast, high force contractions that fatigue quickly due to glycolytic but scant oxidative enzyme capacity. Fast fatigue-resistant (FR) or Type IIa MU have large diameter axons and muscle fibers with large CSA that can sustain relatively high force contractions due to high concentrations of both glycolytic and oxidative enzymes. The primary differences among the three muscle fibers are attributed to variation in mitochondrial density (high oxidative capacity), excitation-contraction coupling mechanism, speed of $\mathrm{Ca}++$ handling via sarcoplasmic reticulum and myosin ATPase. This mosaic architecture provides skeletal muscle with the ability to cope with metabolic demands during skeletal muscle recruitment which varies based on the intensity of exercise.

It is well recognized that during volitional exercise, the recruitment of skeletal muscle follows Henneman's size principle; where small size motor units are recruited first followed by large size based on central nervous system drive [46]. During FES of a peripheral nerve or motor point, however, recruitment of motor units is physiologically reversed based on size and myelination properties of the peripheral MU; electricity flows through the point of least resistance such that large, myelinated FF and FR MU are recruited before $S$ units. Subsequently, mechanical efficiency is markedly diminished resulting in relatively rapid fatigue and declining force output with time in response to FES [47]
We have previously studied the impact of different stimulation parameters on skeletal muscle recruitment. Increasing the amplitude and pulse duration of the electrical stimulus increases the cross-sectional area of skeletal muscle activation during stimulation and is accompanied by increase in the evoked torque. Increasing the frequency of the pulse stimulation results in similar increases in the evoked torque but not the activated area $[48,49]$. In a follow up study, when the frequency of the pulses was altered from 25 to $10 \mathrm{~Hz}, \%$ fatigue increased from 39 to $76 \%$. The same observation regarding $\%$ fatigue was not noticed when pulse duration was altered from 150 to 450 or when the amplitude of the current was changed that could evoke 45 to $75 \%$ of maximum voluntary contraction [50]. Chronic applications of electrical stimulation at 10,5 , and $2.5 \mathrm{~Hz}$ delivered for 10 months in rabbit muscle resulted in conversion of fast twitch to slow twitch muscle fibers, and was accompanied by a decline in muscle mass and isometric tension [51,52].

\section{Truncal stabilization}

Individuals with cervical and high thoracic SCI commonly suffer truncal instability as result of the paralysis of core trunk muscles such as trunk extensors and flexors. Loss of trunk control may lead to a number of predisposing factors such as muscle imbalance and contracture, kyphosis, scoliosis, mechanical back pain, pressure ulcers, and undue pressure on internal organs that may compromise their function [35]. Lack of appropriate trunk control may also lead to imbalance in upper extremities, abnormal reaching techniques or poor balance during transfers [53]. Davis et al. surgically implanted neuroprosthetics for standing and transfers after SCI in a group of 12 volunteers with chronic paralysis. The implanted electrodes were used to activate the lumbar erector spinae muscles to improve trunk seated posture, anterior pelvic tilting and extended forward reach by $8 \mathrm{~cm}$. The effort and assistance required for transfers were reduced for users with midlevel tetraplegia, although the maneuvers were not independent [54].

Wilkenfeld and colleagues performed a simulation study to determine the feasibility of using FES for controlling and stabilizing the seated position after SCI [55]. Their subject was a volunteer with T6 motor and sensory complete SCI that had previously received an implanted FES system for earlier experiments. The FES system included electrodes inserted 
bilaterally at the T12-L1 spinal roots to activate lumbar erector spinae, epimysial electrodes sutured to the primary nerve entry points of the gluteus medius and semimembranous bilaterally. The sitting mechanics supported by FES of the spinal cord injured volunteer was then measured three dimensionally and compared to a model. The authors concluded that FES of the hip and trunk musculature in persons with SCI is feasible and may improve sitting mechanics [55].

\section{Cough}

Respiratory problems are a major cause of death in the acute and chronic phases of cervical and high thoracic spinal cord injury. The intercostal and abdominal muscles become paralyzed due to the SCI lesion, reducing the ability to cough and clear secretions. In addition to clogging breathing airways, the inability to cough increases the risk of respiratory-infection and can lead to atelectasis (a collapsed or airless state of the lungs). Using a cat model, it was demonstrated that intermittent high-frequency FES can maintain the pressure-generating capacity of expiratory muscles over the entire vital capacity range, as well as prevent muscle atrophy by preserving muscle weight and fiber type [56]. Thus FES can be applied to enhancing respiratory function beyond basic preservation of free breathing.

Several studies have provided evidence that support the use of FES for assisting cough and secretion clearance in persons with tetraplegia. Linder demonstrated that FES with electrodes placed over the abdominal muscles increased maximal expiratory pressure (MEP) and cough in individuals with tetraplegia [57]. Over a decade later, Cheng et al. studied the effect of FES surface electrodes over the abdomen and chest on cough capacity and prevention of pulmonary complications in twenty-six individuals with acute tetraplegia. After four weeks of FES, the therapy group displayed significant improvement in peak expiratory flow, forced expiratory volume in one second, forced vital capacity, maximal expiratory pressure and maximal inspiratory pressure compared to controls [58]. Improvements were maintained up to six months after therapy, and those in the FES group also had fewer pulmonary complications in the follow-up period. In 2007, Lim and colleagues demonstrated that truncal posterolateral electrode placement produced greater gastric and esophageal twitch pressures with FES to better assist with cough in high cervical spinal cord injured indi- viduals [59]. Similar findings were demonstrated by Lee et al., following successful decannulation of a 65 year-old man with C4 ASIA $\mathrm{C}$ tetraplegia that had suffered recurrent bouts of pneumonia but responded well to FES [60]. Gollee et al. evaluated the feasibility and effectiveness of an automatic abdominal FES system, synchronized with the subjects' voluntary breathing activity. Four subjects with complete C4-C6 tetraplegia used the system, with significant increases in tidal volume during quiet breathing and in cough peak flow observed. Respiratory rate during quiet breathing decreased in all subjects when stimulated, whereas minute ventilation increased. The automatic stimulation system notably augmented spontaneous breathing and coughing in patients with tetraplegia, and suggested a means of respiratory support for SCI patients with reduced respiratory capacity [61]. Recently, a fully implantable electrical stimulation system was surgically placed in the lower thoracic cords of 9 persons with cervical SCI and weak cough, and demonstrated near maximal activation of the expiratory muscles with the generation of high peak airflow rates and positive airway pressures in the range of those observed with maximum cough efforts in healthy persons [62].

\section{Upper Extremity (UE)}

It is common for individuals with SCI above C7 to have limited arm and/or hand function that could limit the completion of activities of daily living (ADLs) such as hand and face washing, eating, grooming, hygiene, dressing and transfers. Although individuals with cervical SCI may be provided assistive devices or orthoses to complete their functional tasks, this alternative paradigm is compensatory and does not improve motor functional gains. Restoration of UE function has been attempted through hand surgery [6367], somatosensory stimulation [68,69], and functional electrical stimulation via upper extremity neuroprostheses [70-75].

The first generation (see Fig. 2) of upper extremity neuroprosthesis technology (Freehand system) was reported in the mid-1980s and involved implantation of 8-epimyseal electrodes in wrist and hand muscles, including flexor digitorum profundus (FDP) and superficialis (FDS), flexor pollicis longus (FPL), adductor pollicis (ADP), abductor pollicis brevis (AbPB), extensor digitorum communis (EDC), extensor pollicis longus (EPL); one electrode was sutured to the subcutaneous fascia near the clavicle for sensory feedback [74]. 


\section{Functional Electrical Stimulation Hand Grasp System}

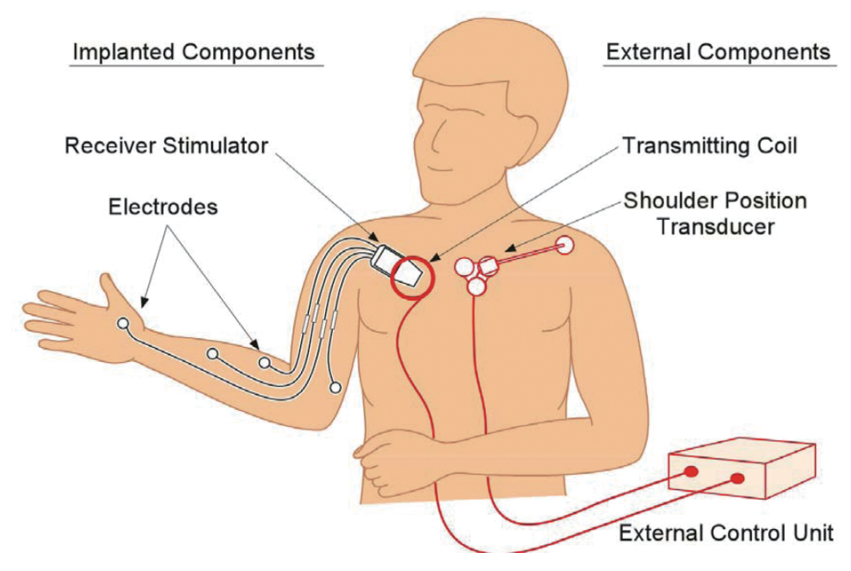

Fig. 2. 1st Generation FreeHand system for upper extremity movement and grasp.

The primary goal of the implanted electrodes was to achieve myoelectric control to improve hand grasp and elbow extension in individuals with cervical SCI [71, 73-79]. More recently, Kilgore et al. [72] have developed a second-generation neuroprosthesis that consists of 12 stimulating electrodes, 2 EMG signal recording electrodes, an implanted stimulator-telemeter device, an external control unit and a transmit/receive unit (see Fig. 3). The EMG recording electrode for distal grasp was placed at extensor carpi radialis longus (ECRL) or brachioradialis $(\mathrm{Br})$, whereas the EMG recording electrode for on/off control was placed at the more proximal trapezius or platysma. After successfully implanting the system in individuals with high SCI, pinch force and grasp function were significantly increased for all three participants, notably improving ADL tasks such as using a fork, brushing hair, answering the phone, moving a book, eating finger foods, and drinking [72].

A less invasive form of UE FES is the commercially available Handmaster neuroprothesis (NESS 200) which combines hand/wrist support with integrated surface electrical stimulation electrodes that are positioned to stimulate wrist extensor, flexor, and the thenar eminenence muscle groups (see Fig. 4). This stimulation technique has been documented to be safe and effective in enhancing specific tasks (telephone pickup, eating with fork, lifting objects) of UE functions in individuals with C5-C6 SCI; improvements reported after 1 week of use and all participants were able to don and doff the orthoses independently [80].

Although it would appear intuitive that FES for UE exercise would be beneficial, few studies to date have demonstrated significant efficacy. One cross-over study demonstrated no significant training effect for
FES above that of isotonic exercise alone in persons with cervical SCI [81]. Conversely, FES-assisted arm crank ergometry (ACE) was noted to improve voluntary strength and control of elbow extensors after 8 weeks of training compared to ACE alone [82]. A recent review concluded that that UE FES training may benefit UE function, but that additional research should be conducted [83].

\section{Lower extremity}

Functional standing and restoration of ambulation is a primary desire for many with SCI. Systems for standing and transfers have evolved from surface stimulation of underlying muscles through overlying skin and fascia to surgically implanted electrical leads which have been found to be superior in muscle activation, force production and time savings [54,84,85]. A necessary interim phase of technological development involved placement and testing of chronic indwelling percutaneous electrodes; once feasibility had been demonstrated, the technology advanced to include siliconeenclosed helical wire electrodes connected to an eightchannel implantable receiver/stimulator [85]. The surgical technique involved placement of indwelling electrodes to bilateral erector spinae, gluteus maximus, semimembranosus and vastus lateralis muscles [84]. The implanted neuroprosthesis (see Fig. 5) has been demonstrated to be sufficient for most users to independently stand and release one hand from a support device to manipulate objects and to perform monitored swing-to ambulation; transfers for higher levels of SCI 


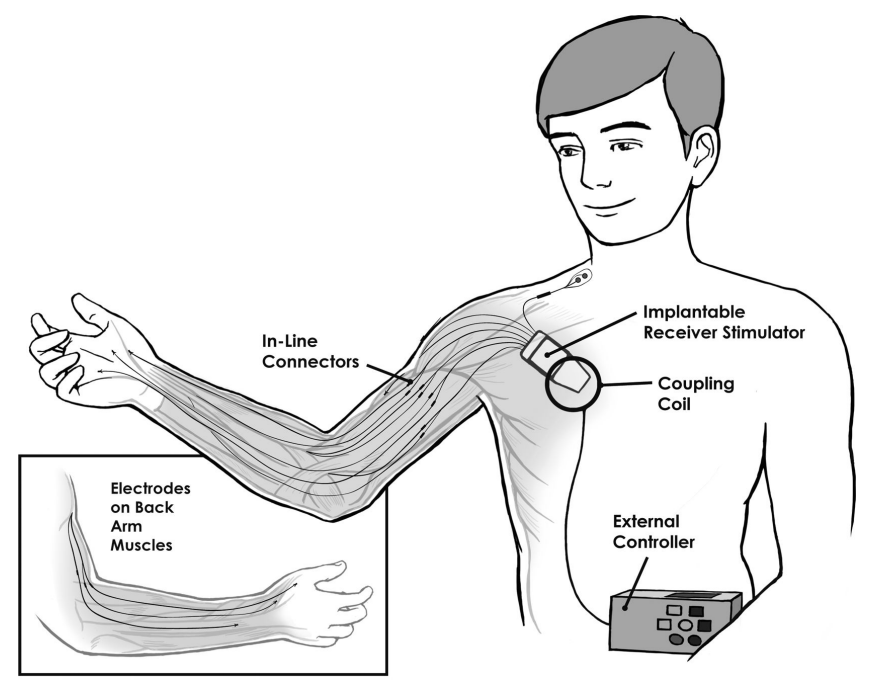

Fig. 3. 2nd Generation FreeHand system.

(above mid-thoracic) required less effort and assistance but were not independent [54]. Of note, FES exercise was employed for at least 6 weeks prior to (via surface stimulation) and after implantation of electrodes before the system was utilized for standing to ensure adequate muscle strength and endurance; this protocol and surgical implantation technique has been employed in several sites across the U.S. although long-term follow up of the multicenter trial has not yet been reported. The system has been augmented with implanted electrodes to ankle dorsiflexors and a customized exoskeletal orthosis to facilitate ambulation and stair climbing; preliminary reports appear promising [86].

Inability to ambulate negatively impacts a person functionally, physiologically and psychologically [8689]. For individuals with limited lower extremity active movement due to incomplete SCI, orthotics provide limited success due to their bulk and weight and usually need augmentation with walking aids and/or manual assistance provided by a second party. Such activity is adequate for exercise but reduces practical functionality [88]. Two major limitations for regaining functional ambulation with orthotics alone are 1) disordered spinal reflexes that negatively impact locomotor function, and 2) extreme workloads placed upon the upper extremities that cause premature muscle fatigue $[88,90$, 91]. Lower extremity FES has subsequently been used to augment orthotics for functional standing and ambulation in order to overcome these limitations. Although the addition of muscular assistance from lower extremities via FES has improved ambulation by means of eliciting coordinated reflex-based movements and reduced

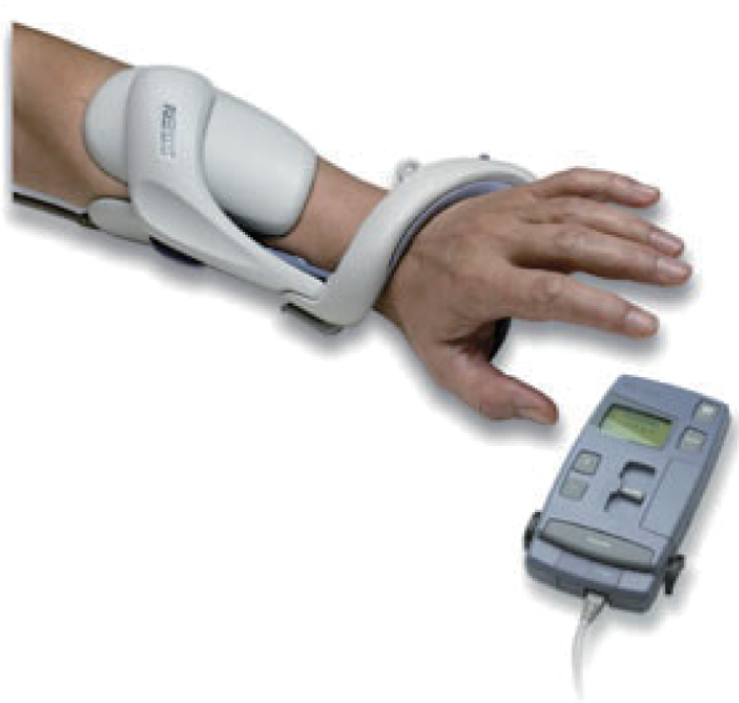

Fig. 4. Ness H200 Hand System.

the overall energy demands on the upper extremities, energy demand still remains very high, irrespective of electrode placement (intramuscular or on the surface above the targeted musculature) [88,90-92].

Over the last three decades there has been a concerted effort to enhance the quality of orthotic devices in order to better accommodate an FES-orthotic hybrid ambulation system. The Louisiana State University reciprocating gate orthosis (RGO) is a passive mechanical hip-knee-ankle-foot orthosis (HKAFO) made of polypropylene with aluminum medial and lateral uprights extending from foot to knee and the knee to hip 


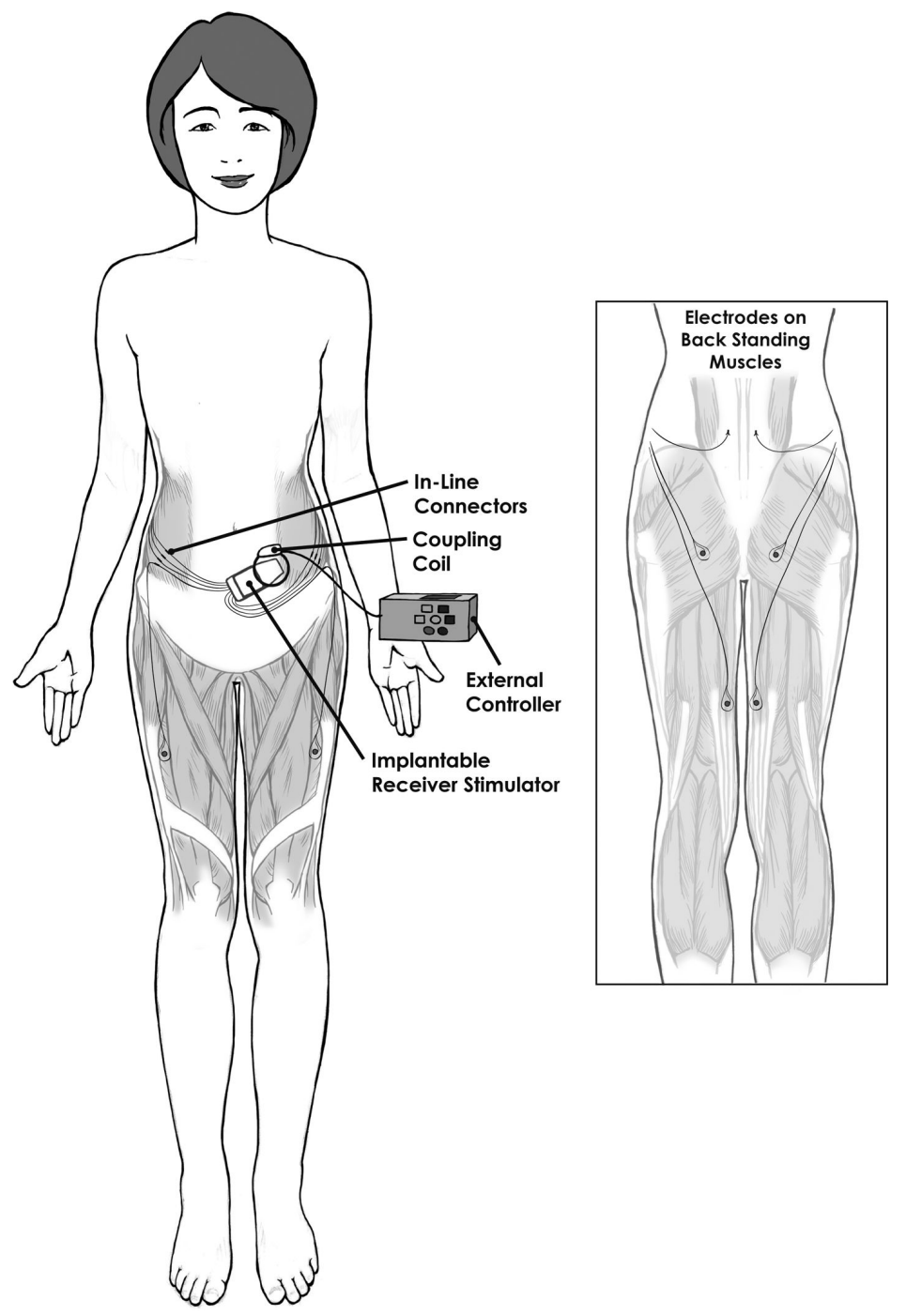

Fig. 5. Cleveland FES Standing/Transfer System.

to promote knee and ankle stability and promote vertical balance and posture [90]. A 4-month training protocol including preparatory ambulation, LE FES, and combined FES-RGO utilization significantly reduced energy expenditure for walking, but appeared impractical for community mobility [90]. Nene and Jennings added intramuscular glutei FES to the hip guidance orthosis (HGO) or parawalker and produced modest benefits in increased speed of ambulating with crutches, but found many of the same limitations that were experienced with the FES-RGO system, i.e., slow walking, difficult donning, difficult transfers, and less than desirable aesthetics [93]. Comparison of the commercially available advanced reciprocal gait orthosis (ARGO) with and without FES and Parastep ${ }^{\circledR}$ have demon- strated the latter to be more user-friendly (see Fig. 6), but the ARGO and ARGO+FES utilized significantly less energy over similar distances [94]. All three systems for ambulation utilized significantly higher energy expenditure than did wheelchair locomotion over the same distances; higher energy costs had previously been implicated in non-compliance of the orthotic systems when compared to wheelchair locomotion [95]. In order to reduce total energy expenditure, a braking mechanism has been incorporated into the hip and knee joints of orthoses utilized at the University of Minnesota that regulates swing phase leg motion and momentarily locks the joints during the double support stand phase in the gait cycle, allowing brief deactivation of muscular FES and subsequently reducing fatiguing and 


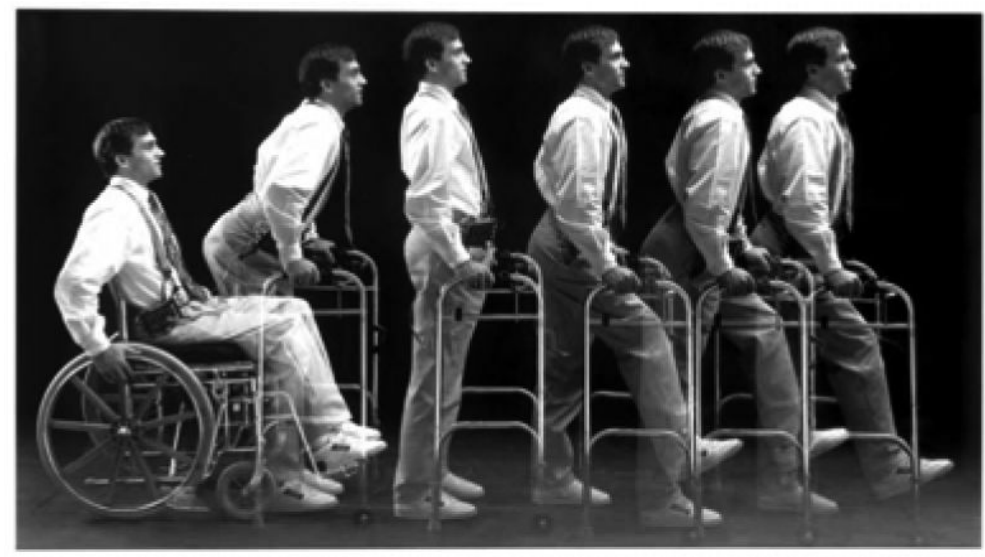

Fig. 6. Parastep FES-HKAFO hybrid system for walking.

increasing distance walked [96] FES has also been used to augment partial weight bear treadmill training with encouraging results [91,97].

\section{Exercise}

Exercise capacity in SCI is limited by blunted sympathetic responses due to autonomic dysfunction, neurogenic hypotension, circulatory hypokinesis, adaptive myocardial atrophy with reduced cardiac output, impaired cardiac chronotropic/inotropic capacity, reduced tidal volumes, bronchiolar constriction, impaired ventilatory capacity, upper extremity overuse syndrome, impaired upper and lower extremity proprioception, spasticity, osteopenia/osteoporosis, neurogenic skin, neurogenic bowel, neurogenic bladder, impaired thermoregulation, and autonomic dysreflexia [98-100]. Even in individuals without SCI, total work capacity using UE versus LE is significantly reduced; energy expenditure is similarly diminished. For persons with SCI, UE work is further compromised by sympathetic blunting and circulatory hypokinesis which cause additional reductions in cardiac output despite increased perceived effort. LE FES can offset some of these physiological limitations by activating the muscle pumps responsible for venous blood flow return. It is also possible that FES causes some degree of autonomic dysreflexia (AD) which may offset circulatory hypokinesis, although $\mathrm{AD}$ requires close hemodynamic monitoring to ensure afterload does not impair cardiac output.

In use for over 40 years, LE FES has been refined with increasingly complex computer technology to be used as an exercise enhancement tool for patients with spinal cord injury. Phillips in 1987 proposed medical guidelines for patient participation in FES rehabilitation, including medical criteria for inclusion and exclusion [101]. FES of the lower extremities, particularly in repetitive leg cycle ergometery (LCE) can be used to stimulate strength [102-104] and endurance [102, $103,105]$, and has the potential to improve energy expenditure, increase stroke volume [106,107], increase total body peak power output, $\mathrm{VO}_{2 P e a k}$ and ventilatory rate [105,108,109], during the FES session; these effects do not persist when tested under conditions of UE work. Chronic FES LCE effects include the reversal of myocardial disuse atrophy [110], increased HDL levels [111], improve body composition [112], and possibly increase lower extremity bone mineral density [113-115].

Bone mineral loss as determined by DEXA is rapid and linear within the first 4 months of SCI, occurring to a greater extent in the pelvis and lower extremities in both tetraplegic and paraplegic individuals [116]. Homeostasis at $67 \%$ of original bone mass is achieved at about 16 months post-injury, barely above fracture threshold. Several studies have attempted to reverse the osteopenic process using FES of the lower extremities, but to date few have demonstrated significant improvement [113,115,117-120]. BeDell et al. demonstrated a trend toward increasing density of the lumbar spine but not the pelvis after 34 weeks of twice weekly FES sessions with leg cycle ergometry (LCE) [121]. Hangartner et al. reported a slowing of the expected rate of bone loss [114]. Mohr et al. demonstrated 10\% increased bone mineral density (BMD) at the proximal tibia after 12 months of training, but BMD remained $40 \%$ less than that of non-SCI controls [117]. Similarly, Chen et al. demonstrated significant improvements at proximal tibia and distal femur after 6 months FES 


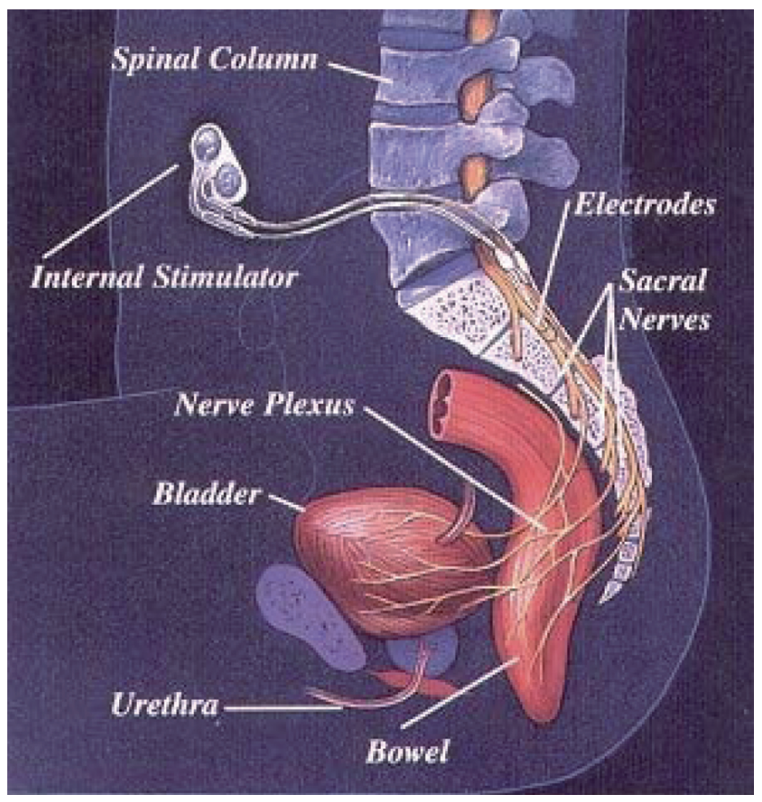

Fig. 7. NeuroControl Vocare Bowel/Bladder Stimulator.

training, but BMD in these areas remained $>40 \%$ below able-bodied controls [115]. Conversely, Bloomfield et al. (1996) found increased bone mineral density for the lumbar spine but not LE after 3 months of training at a threshold power output of 18 watts with FES-LCE [113].

\section{Bladder, bowel and sexual function}

While standing, walking and ADLs would seem of paramount importance to persons with SCI, most express higher priorities for bladder, bowel and sexual function [122]. Electrical stimulation of sacral roots has been demonstrated to be beneficial for these functions since the 1970's when animal models were translated to clinical opportunities for persons with SCI. Sacral nerve roots provide somatic control over external urethral and anal sphincters via the pudendal nerve, while also providing parasympathetic stimulation of the bladder, rectum, sphincters and erectile tissue through pelvic splanchnic nerves. Brindley's group reported on their initial experiences in the late 1970's and early 1980's in which increasing numbers of the FinetechBrindley bladder FES devices were successfully placed in Europe [123,124]. Most included dorsal rhizotomies in which sacral sensory fibers (S2-4) were sacrificed to reduce the likelihood of detrusor sphincter dyssynergia and upper urinary tract deterioration, with the stimulat- ing electrodes for most patients placed intrathecally at the level of the L5 vertebrae [124]. The surgical technique has been somewhat refined over the years, with electrodes currently being placed bilaterally and extradurally to reduce the risk of nerve trauma and spinal fluid leak. Notably, the stimulation parameters can be modified to generate sustained bladder contractions while permitting the sphincter to rapidly relax during periods of no stimulation; stimulation parameters continue to be modified to optimize the detrusor sphincter relationship $[123,125]$. Initially available only in Europe, the device was tested [126] and briefly marketed in the U.S. but is no longer commercially available. As with other implantable systems, the internal components include a receiver/stimulator and extradural electrodes (see Fig. 7), while the external components include an external controller, transmitter, cable, tester, battery charger and power cord. Notable benefits have included improved or absolute continence, increased bladder capacity and compliance, reduced bladder pressures and upper tract deterioration, fewer urinary tract infections and reduced bladder-induced autonomic dysreflexia, while implant failures and repair were relatively rare [124,126,127].

A notable side effect of the Finetech-Brindley bladder FES device was that it could increase colo-rectal motor activity, i.e., stimulate defecation [126,128130]. Adjustment of the stimulation parameters led to selective bowel evacuation, requiring less time for bowel care and improved bowel function, without an increase in bowel incontinence [126,131]. Despite an excellent cost analysis demonstrating significant cost benefits using the neuroprosthesis provided by Creasey et al. (2000), the U.S. version of the Finetech-Brindley FES device is no longer commercially available.

Sustained electrical stimulation of sacral anterior nerve roots, especially $\mathrm{S} 2$, can produce penile erection, but use of the Finetech-Brindley FES device for intercourse in persons with SCI has not yet been clinically tested [132]. However, successful electroejaculation has been demonstrated in persons with SCI since the late 1940's, utilizing an electrical probe placed in the anterior rectum near the prostate and seminal vesicles [133-136]. Electrical stimulation is administered in a wave-like pattern with progressively increasing voltage (1-2 V increments) until ejaculation occurs.

\section{Future applications}

A summary of basic research findings is listed in Table 2. Commercial success for a variety of FES systems 
Table 2

Description of FES studies in people with SCI according to the function

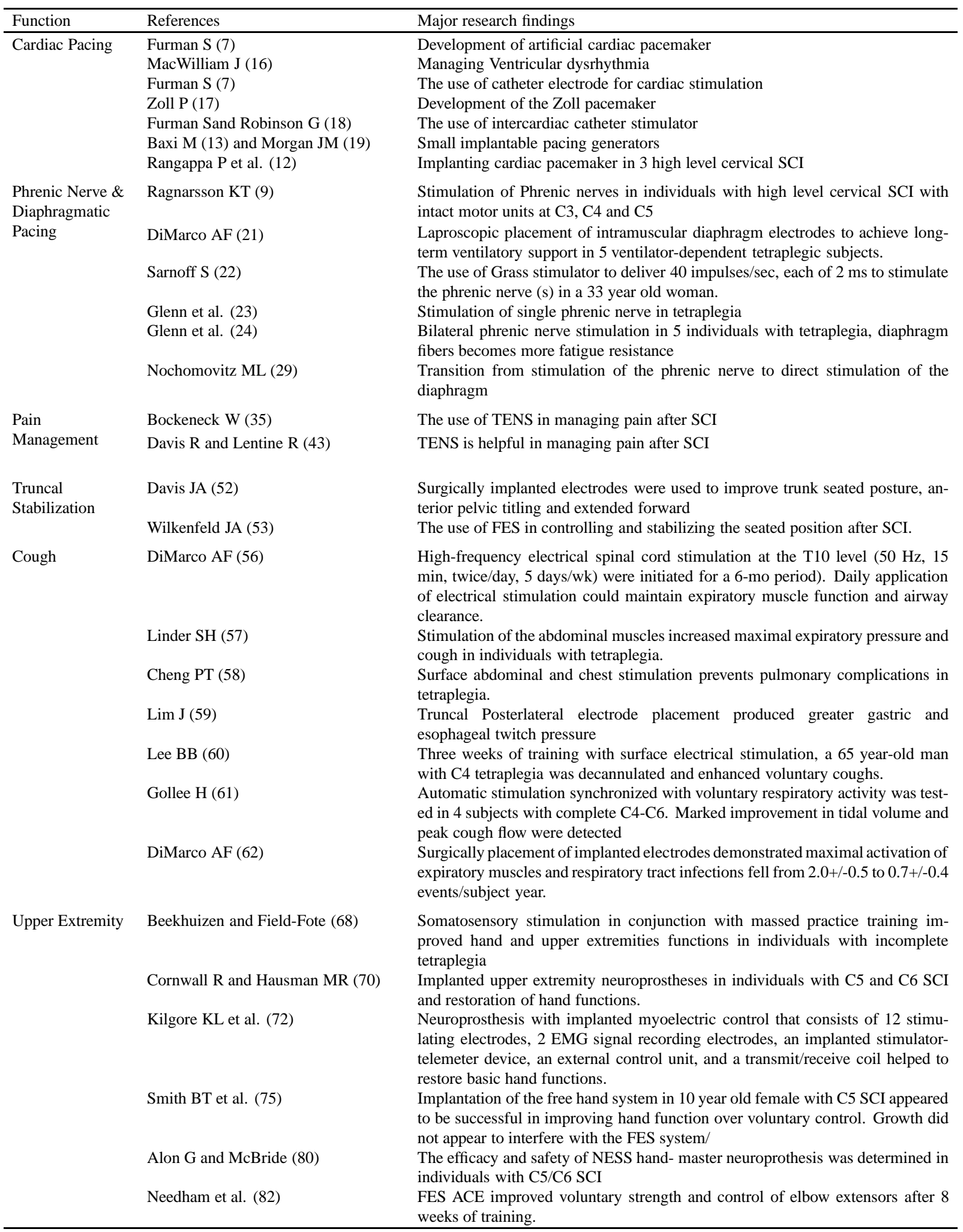


Table 2, continued

\begin{tabular}{|c|c|c|}
\hline \multicolumn{3}{|l|}{ Function } \\
\hline \multirow[t]{5}{*}{ Lower Extremity } & Davis JA et al. (84) & $\begin{array}{l}\text { The development of } 8 \text { channel implanting electrical stimulation for standing } \\
\text { and transfer in individuals with SCI which has been successfully applied in } 7 \\
\text { individuals. }\end{array}$ \\
\hline & Kobetic R et al. (86) & $\begin{array}{l}\text { A hybrid system of exoskeleton and multichannel implanted electrical stimulation } \\
\text { were used to achieve standing, stepping, and stair climbing in individuals with } \\
\text { SCI. }\end{array}$ \\
\hline & Maxwell DJ et al. (89) & The use of FES to offer standing and walking in individuals with incomplete SCI \\
\hline & Field-Fote EC and Tepavac D (91) & $\begin{array}{l}\text { Improvement of inter-limb coordination following } 12 \text {-week program of body } \\
\text { weight supported treadmill and electrical stimulation. }\end{array}$ \\
\hline & Solomonow M et al. (92) & $\begin{array}{l}\text { The RGO Generation II reciprocating gait orthosis in conjunction with electrical } \\
\text { stimulation resulted in improvement in energy expenditure and walking speed in } \\
\text { six patients with thoracic SCI. }\end{array}$ \\
\hline \multirow[t]{12}{*}{ Exercise } & Faghri et al. (102) & The use of FES to achieve muscular strength in individuals with SCI \\
\hline & Ragnarsson KT (103) & $\begin{array}{l}\text { Increased strength, endurance, and bulk of stimulated muscles were noted fol- } \\
\text { lowing participation in FES-induced exercise program. }\end{array}$ \\
\hline & Rodgers MM et al.(104) & $\begin{array}{l}\text { Leg extension exercise with electrical stimulation for } 36 \text {-session suggested in- } \\
\text { crease in knee extensor muscle group performance and knee range of motion. }\end{array}$ \\
\hline & Hooker SP et al. (105) & $\begin{array}{l}\text { FES cycling for } 36 \text { sessions resulted in improvement in cardiovascular parame- } \\
\text { ters, oxygen uptake, cardiac output and lower total peripheral rsitnace. }\end{array}$ \\
\hline & Figoni SF et al. (106) & $\begin{array}{l}\text { FES cycling significantly impact cardiovascular response while passive cycling } \\
\text { produced no cardiovascular adapations }\end{array}$ \\
\hline & Hjeltnes $N$ et al. (107) & $\begin{array}{l}\text { FES cycling resulted in improvement in whole body insulin stimulated glucose } \\
\text { uptake and GLUT4 protein expressions. }\end{array}$ \\
\hline & Hooker SP et al. (111) & $\begin{array}{l}\text { Hybrid exercise using both arm crank ergometer and FES creates greater cardio- } \\
\text { vascular and metabolic adaptations than either of them applied separately. }\end{array}$ \\
\hline & Bauman WA et al. (112) & $\begin{array}{l}\text { FES cycling resulted in improvement in body composition and HDL profile in } \\
\text { individuals with SCI. }\end{array}$ \\
\hline & Bloomfield SA et al. (113) & $\begin{array}{l}\text { FES cycling resulted in increasing bone mineral density at lumbar region. Those } \\
\text { who exercised at } 18 \mathrm{~W} \text { or more demonstrate increasing in BMD at the distal end } \\
\text { of the femur. }\end{array}$ \\
\hline & Hangartner TN et al. (114) & $\begin{array}{l}\text { FES cycling resulted in attenuation of bone loss in proximal and distal tibia after } \\
\text { being measured with computed tomography. }\end{array}$ \\
\hline & Mohr T et al. (117) & $\begin{array}{l}\text { FES cycling for } 12 \text { months resulted in increasing BMD at the proximal tibia by } \\
10 \% \text {. }\end{array}$ \\
\hline & Needham-Shropshire BM et al. (119) & $\begin{array}{l}\text { Parastep 1system failed to show adaptations on bone mineral density after axial } \\
\text { loading. }\end{array}$ \\
\hline \multirow{8}{*}{$\begin{array}{l}\text { Bladder, } \\
\text { Bowel and Sexual } \\
\text { function }\end{array}$} & Brindley GS (123) & $\begin{array}{l}\text { Implanted electrical stimulation for bladder management in individuals with SCI } \\
\text { using sacral anterior stimulation. }\end{array}$ \\
\hline & Bhadra N et al. (124) & $\begin{array}{l}\text { In dogs, selective activation of sacral ventral roots combined with dorsal rhi- } \\
\text { zotomy may provide means of low-pressure continuous voiding in neurological } \\
\text { impairment. }\end{array}$ \\
\hline & Creasey GH et al. (125) & $\begin{array}{l}\text { Implanted neuroprosthesis is a safe and effective method for management of the } \\
\text { neurogenic bladder and bowel in individuals with SCI. }\end{array}$ \\
\hline & Binnie NR et al. (127) & $\begin{array}{l}\text { Anterior sacral nerve root stimulator increased the frequency of defaecation in } \\
\text { individuals with paraplegia. }\end{array}$ \\
\hline & Johnston TE et al. (128) & $\begin{array}{l}\text { The feasibility of using the Praxis multifunctional implanted FES system for up- } \\
\text { right mobility and aiding aspects of bladder and bowel function was demonstrated } \\
\text { with three subjects with thoracic level SCI. }\end{array}$ \\
\hline & Brindley GS (130) & $\begin{array}{l}\text { Sustained electrical stimulation of sacral anterior nerve roots, especially S2, can } \\
\text { produce penile erection }\end{array}$ \\
\hline & Sonksen J and Ohl DA (132) & $\begin{array}{l}\text { PVS and EEJ have been successfully performed in patients who failed to obtain } \\
\text { ejaculation by masturbation, this may enhance fertility. }\end{array}$ \\
\hline & Sramkova T et al. (134) & $\begin{array}{l}\text { Combined use of electroejaculation and intracytoplasmic sperm injection is ex- } \\
\text { cellent management for the paraplegic men who wish to have children. }\end{array}$ \\
\hline
\end{tabular}


has been limited due to the relatively small market, relatively high cost of systems and their implantation, reluctant third party payors, technological shortcomings and insufficient clinical trials to scientifically document benefits [9]. Persons with tetraplegia primarily desire hand and upper extremity function, while those with paraplegia list sexual function as their most pressing desire; secondary priorities vary among individuals but include bladder and bowel continence, trunk stability, walking, pain management and exercise interventions $[122,136]$. Consumers would prefer easily accessible, user-friendly devices that are reliable, durable, adjustable, inexpensive, and modifiable.

Implantable systems for diaphragmatic pacing may become viable methods to "bridge" the period an individual is on passive mechanical ventilation in order to minimize diaphragmatic atrophy, as well as to minimize wean times. Systems for hand and upper extremity function are already capitalizing on EMG activity from intact proximal musculature to proportionally drive stimulated muscles. The need to continue to focus on FES gait systems that provide optimal FES, orthotic, and ambulatory aid innovations to enhance the functionality of ambulation for those with SCI is of great importance. Providing a more natural gait and less energy demand appear to be key factors for success. Modular components are being designed to link several different systems within the same individual, such that multiple implantable systems (e.g., bilateral UE, trunk/abdomen, bowel/bladder and LE) may be linked and modifiable.

FES-LCE and resistance training have great potential for providing therapeutic and wellness benefits to individuals with SCI. Future focus needs to be directed toward quantifying optimal intensity (workload), frequency, and duration of exercise sessions to promote healthy musculoskeletal and cardiovascular adaptations, and perhaps just as important energy expenditure for obesity reduction. Home exercise programs seem to be an area of potential that may help promote healthier more active lifestyles. Encouraging public and private fitness and wellness centers to include wheelchair accessible equipment and staffing with basic knowledge to assist the needs of individuals with SCI are also important for the advancement of physiological and psychological benefits of those with SCI.

Finally, the electrical stimulation patterns for FES implantable bowel/bladder systems have recently been modified to selectively block certain elements to allow variable control/timing of bladder or bowel contractions relative to their respective sphincters. As more is learned about modulating electrical signals, greater degrees of control may be gained for these functions, as well as for those systems utilized in UE, trunk/abdomen and LE applications.

\section{References}

[1] D. Stillings, The first use of electricity for pain treatment, Minneapolis, MN: Medtronic, Inc., 1971.

[2] B. Baigrie, Electricity and Magnetism: A Historical Perspective, Greenwood Press; 2006.

[3] P.L. Gildenberg, History of electrical neuromodulation for chronic pain, Pain Medicine 7 (2006), S7-S13.

[4] T.G. Bolwig and M. Fink, Electrotherapy for Melancholia The Pioneering Contributions of Benjamin Franklin and Giovanni Aldini, Journal of Ect 25(1) (2009), 15-18.

[5] A. Rockwell, The Medical and Surgical Uses of Electricity, New York: E.B. Treat and Company, 1903.

[6] J. Bhatt, Electric Stimulation in Medical Sciences: from Basic to Applied, Journal of Applied Basic Medical Sciences 3(3) (2001), 49-51.

[7] S. Furman, The early history of cardiac pacing, Pace-Pacing and Clinical Electrophysiology 26(10) (2003), 2023-2032.

[8] NSCISC: Spinal Cord Injury Facts and Figures at a Glance. In. Birmingham, AB: National Spinal Cord Injury Statistical Center; 2010.

[9] K.T. Ragnarsson, Functional electrical stimulation after spinal cord injury: current use, therapeutic effects and future directions, Spinal Cord 46(4) (2008), 255-274.

[10] B.H. Dobkin, Do electrically stimulated sensory inputs and movements lead to long-term plasticity and rehabilitation gains? Current Opinion in Neurology 16(6) (2003), 685-691.

[11] M.A. Wood and K.A. Ellenbogen, Cardiac pacemakers from the patient's perspective, Circulation 105(18) (2002), 21362138.

[12] P. Rangappa, J. Jeyadoss, A. Flabouris, J.M. Clark and R. Marshall, Cardiac pacing in patients with a cervical spinal cord injury, Spinal Cord 48(12) (2010), 867-871.

[13] M. Baxi, First Artificial Pacemaker: A Milestone in History of Cardiac Electrostimulation, Asian Student Medical Journal 2 (2003).

[14] D. Schechte, Early Experience With Resuscitation By Means Of Electricity, Surgery 69(3) (1971), 360-\&.

[15] O. Aquilina, A Brief History of Cardiac Pacing, Images in Paediatric Cardiology 27 (2006), 17-81.

[16] J. MacWilliam, Some Applications of Physiology to medicine. II Ventricular fibrillation and sudden death, British Medical Journal 2 (1923).

[17] P. Zoll, Resuscitation of the heart in ventricular standstill by external electric stimulation, New England Journal of Medicine 247 (1952), 768-771.

[18] S. Furman and G. Robinson, Use of intracardiac pacemaker in correction of total heart block, Surgical Forum 9 (1958), $245-252$.

[19] J.M. Morgan, Basics of cardiac pacing: selection and mode choice, Heart 92(6) (2006), 850-854.

[20] A. Agrawal, J. Timothy, R. Cincu, T. Agarwal and L.B. Waghmare, Bradycardia in neurosurgery, Clinical Neurology and Neurosurgery 110(4) (2008), 321-327.

[21] A.F. DiMarco, R.P. Onders, A. Ignagni, K.E. Kowalski and J.T. Mortimer, Phrenic nerve pacing via intramuscular di- 
aphragm electrodes in tetraplegic subjects, Chest 127(2) (2005), 671-678.

[22] S. Sarnoff, E. Hardenbergh and J. Whittenberger, Electrophrenic respiration, Science $\mathbf{1 0 8}$ (1948), 482.

[23] W.W.L. Glenn, J.F. Hogan, W.G. Holcomb, R. Yasuda, J.M. Ohare and A.J. McLaughl, Total Ventilatory Support In A Quadriplegic Patient With Radiofrequency Electrophrenic Respiration, New England Journal of Medicine 286(10) (1972), 513-\&.

[24] W.W.L. Glenn, J.F. Hogan, J.S.O. Loke, T.E. Ciesielski, M.L. Phelps and R. Rowedder, Ventilatory Support By Pacing Of The Conditioned Diaphragm In Quadriplegia, New England Journal of Medicine 310(18) (1984), 1150-1155.

[25] G. Creasey, J. Elefteriades, A. DiMarco, P. Talonen, M. Bijak, W. Girsch and C. Kantor: Electrical stimulation to restore respiration, Journal of Rehabilitation Research and Development 33(2) (1996), 123-132.

[26] A.F. DiMarco, Phrenic nerve stimulation in patients with spinal cord injury, Respiratory Physiology and Neurobiology 169(2) (2009), 200-209.

[27] S. Hirschfeld, G. Exner, T. Luukkaala and G.A. Baer, Mechanical ventilation or phrenic nerve stimulation for treatment of spinal cord injury-induced respiratory insufficiency, Spinal Cord 46(11) (2008), 738-742.

[28] P. Khong, A. Lazzaro and R. Mobbs, Phrenic nerve stimulation: The Australian experience, Journal of Clinical Neuroscience 17(2) (2010), 205-208.

[29] M.L. Nochomovitz, D.K. Peterson and T.A. Stellato, Electrical Activation Of The Diaphragm, Clinics in Chest Medicine 9(2) (1988), 349-358.

[30] W. Mysiw and R. Jackson, Electrical Stimulation, Philadelphia, PA: W.B. Saunders; 2007.

[31] C. Denegar and P. Donley, Managing pain with modalities, New York, NY: McGraw-Hill; 2002.

[32] P.J. Siddall, R.P. Yezierski and J.D. Loeser, Taxonomy and epidemiology of spinal cord injury pain, in: Spinal Cord Injury Pain: Assessment, Mechanisms, Management, (vol. 23), R.P. Yezierski and K.J. Burchiel, eds, 2002, pp. 9-24.

[33] M. Somers, Spinal Cord Injury: Functional Rehabilitation, Prentice Hall; 2001.

[34] J. Bonica, ed., Semantic, epidemiologic, and educational issues, New York, NY: Raven Press; 1991.

[35] W. Bockeneck and P. Stewart, eds, Pain in patients with spinal cord injury, Philadelphia, PA: Williams and Wilkins; 2002.

[36] D. Hooker, Electrical stimulating currents, New York, NY: McGraw-Hill; 2002.

[37] R. Melzack and P.D. Wall, Pain Mechanisms - A New Theory, Science 150(3699) (1965), 971.

[38] J. Tan, Acute and chronic pain, Philadelphia, PA: Elsevier Mosby; 2006

[39] K.M. Foley, I.A. Kourides, C.E. Inturrisi, R.F. Kaiko, C.G. Zaroulis, J.B. Posner, R.W. Houde and C.H. Li, BetaEndorphin - Analgesic And Hormonal Effects In Humans, Proceedings of the National Academy of Sciences of the United States of America 76(10) (1979), 5377-5381.

[40] J. Silfverskiold and R.L. Waters, Shoulder Pain And Functional Disability In Spinal-Cord Injury Patients, Clinical Orthopaedics and Related Research (272) (1991), 141-145.

[41] D.A. Nawoczenski, J.M. Ritter-Soronen, C.M. Wilson, B.A. Howe and P.M. Ludewig, Clinical trial of exercise for shoulder pain in chronic spinal injury, Physical Therapy 86(12) (2006), 1604-1618

[42] T.E. Balazy, Clinical Management of Chronic Pain in Spinal Cord Injury, Clinical Journal of Pain 8(2) (1992), 102-110.
[43] R. Davis and R. Lentine, Transcutaneous nerve stimulation for treatment of pain in patients with spinal cord injury, Surgical Neurology 4 (1975), 100-101.

[44] C. Britell, Chronic Pain in Spinal Cord Injury, Physical Medicine and Rehabilitation: State of the Art Reviews 5 (1991), 71-82.

[45] A.R. Ward and N. Shkuratova, Russian electrical stimulation: The early experiments, Physical Therapy 82(10) (2002), 1019-1030.

[46] E. Henneman, G. Somjen and D.O. Carpente, Functional Significance Of Cell Size In Spinal Motoneurons, Journal of Neurophysiology 28(3) (1965), 560-\&.

[47] L.D. Duffell, N.D. Donaldson and D.J. Newham, Power Output During Functional Electrically Stimulated Cycling in Trained Spinal Cord Injured People, Neuromodulation 13(1) (2010), 50-57.

[48] A.S. Gorgey and G.A. Dudley, The role of pulse duration and stimulation duration in maximizing the normalized torque during neuromuscular electrical stimulation, Journal of Orthopaedic and Sports Physical Therapy 38(8) (2008), 508516.

[49] A.S. Gorgey, E. Mahoney, T. Kendall and G.A. Dudley, Effects of neuromuscular electrical stimulation parameters on specific tension, European Journal of Applied Physiology 97(6) (2006), 737-744.

[50] A.S. Gorgey, C.D. Black, C.P. Elder and G.A. Dudley, Effects of Electrical Stimulation Parameters on Fatigue in Skeletal Muscle, Journal of Orthopaedic and Sports Physical Therapy 39(9) (2009), 684-692.

[51] D. Pette, B.U. Ramirez, W. Muller, R. Simon, G.U. Exner and R. Hildebrand, Influence of Intermittent Long-Term Stimulation on Contractile, Histochemical and Metabolic Properties of Fiber Populations in Fast and Slow Rabbit Muscles, Pflugers Archiv-European Journal of Physiology 361(1) (1975), 1-7.

[52] D. Pette and G. Vrbova, What does chronic electrical stimulation teach us about muscle plasticity? Muscle and Nerve 22(6) (1999), 666-677.

[53] K.A. Curtis, C.M. Kindlin, K.M. Reich and D.E. White, Functional Reach In Wheelchair Users - The Effects Of Trunk And Lower-Extremity Stabilization, Archives of Physical Medicine and Rehabilitation 76(4) (1995), 360-367.

[54] J.A. Davis, R.J. Triolo, J. Uhlir, C. Bieri, L. Rohde, D. Lissy and S. Kukke, Preliminary performance of a surgically implanted neuroprosthesis for standing and transfers - Where do we stand? Journal of Rehabilitation Research and Development 38(6) (2001), 609-617.

[55] A.J. Wilkenfeld, M.L. Audu and R.J. Triolo, Feasibility of functional electrical stimulation for control of seated posture after spinal cord injury: A simulation study, Journal of Rehabilitation Research and Development 43(2) (2006), 139-151.

[56] A.F. DiMarco and K.E. Kowalski, Effects of chronic electrical stimulation on paralyzed expiratory muscles, Journal of Applied Physiology 104(6) (2008), 1634-1640.

[57] S.H. Linder, Functional Electrical-Stimulation To Enhance Cough In Quadriplegia, Chest 103(1) (1993), 166-169.

[58] P.T. Cheng, C.L. Chen, C.M. Wang and C.Y. Chung, Effect of neuromuscular electrical stimulation on cough capacity and pulmonary function in patients with acute cervical cord injury, Journal of Rehabilitation Medicine 38(1) (2006), 3236.

[59] J. Lim, R.B. Gorman, J.P. Saboisky, S.C. Gandevia and J.E. Butler, Optimal electrode placement for noninvasive elec- 
trical stimulation of human abdominal muscles, Journal of Applied Physiology 102(4) (2007), 1612-1617.

[60] B.B. Lee, C. Boswell-Ruys, J.E. Butler and S.C. Gandevia, Surface functional electrical stimulation of the abdominal muscles to enhance cough and assist tracheostomy decannulation after high-level spinal cord injury, Journal of Spinal Cord Medicine 31(1) (2008), 78-82.

[61] H. Gollee, K. Hunt, D. Allan, M. Fraser and A. Mclean, Automatic electrical stimulation of abdominal wall muscles increases tidal volume and cough peak flow in tetraplegia, Technology and Health Care 16(4) (2008), 273-281.

[62] A.F. DiMarco, K.E. Kowalski, R.T. Geertman and D.R. Hromyak, Lower Thoracic Spinal Cord Stimulation to Restore Cough in Patients With Spinal Cord Injury: Results of a National Institutes of Health-Sponsored Clinical Trial. Part I: Methodology and Effectiveness of Expiratory Muscle Activation, Archives of Physical Medicine and Rehabilitation 90(5) (2009), 717-725.

[63] K.D. Anderson, J. Friden and R.L. Lieber, Acceptable benefits and risks associated with surgically improving arm function in individuals living with cervical spinal cord injury, Spinal Cord 47(4) (2009), 334-338.

[64] C.M. Curtin, D.R. Gater and K.C. Chung, Upper extremity reconstruction in the tetraplegic population, a national epidermiologic study, Journal of Hand Surgery-American Volume 30A(1) (2005), 94-99.

[65] K.C. Freehafer, Tendon transfers in tetraplegic patients: The Cleveland experience, Spinal Cord 36(5) (1998), 315-319.

[66] J. Friden and C. Reinholdt, Current concepts in reconstruction of hand function in tetraplegia, Scandinavian Journal of Surgery 97(4) (2008), 341-346.

[67] E.A. Moberg and D.W. Lamb, Surgical rehabilitation of the upper limb in tetraplegia, Hand 12(2) (1980), 209-213.

[68] K.S. Beekhuizen and E.C. Field-Fote, Sensory stimulation augments training in persons with the effects of massed practice tetraplegia, Archives of Physical Medicine and Rehabilitation 89(4) (2008), 602-608.

[69] L.R. Hoffman and E.C. Field-Fote, Cortical reorganization following bimanual training and somatosensory stimulation in cervical spinal cord injury: A case report, Physical Therapy 87(2) (2007), 208-223.

[70] R. Cornwall and M.R. Hausman, Implanted neuroprostheses for restoration of hand function in tetraplegic patients, Journal of the American Academy of Orthopaedic Surgeons 12(2) (2004), 72-79.

[71] M.W. Keith, Neuroprostheses for the upper extremity, Microsurgery 21(6) (2001), 256-263.

[72] K.L. Kilgore, H.A. Hoyen, A.M. Bryden, R.L. Hart, M.W. Keith and P.H. Peckham, An implanted upper-extremity neuroprosthesis using myoelectric control, Journal of Hand Surgery-American Volume 33A(4) (2008), 539-550.

[73] M.J. Mulcahey, R.R. Betz, S.H. Kozin, B.T. Smith, D. Hutchinson and C. Lutz, Implantation of the Freehand System (R) during initial rehabilitation using minimally invasive techniques, Spinal Cord 42(3) (2004), 146-1155.

[74] M.J. Mulcahey, R.R. Betz, B.T. Smith, A.A. Weiss and S.E. Davis, Implanted functional electrical stimulation hand system in adolescents with spinal injuries: An evaluation, Archives of Physical Medicine and Rehabilitation 78(6) (1997), 597-607.

[75] B.T. Smith, M.J. Mulcahey and R.R. Betz, An implantable upper extremity neuroprosthesis in a growing child with a C5 spinal cord injury, Spinal Cord 39(2) (2001), 118-123.
[76] S. Carroll, C. Cooper, D. Brown, G. Sormann, S. Flood and M. Denison, Australian experience with the Freehand System (R) for restoring grasp in quadriplegia, Australian and New Zealand Journal of Surgery 70(8) (2000), 563-568.

[77] P. Taylor, J. Esnouf and J. Hobby, The functional impact of the Freehand System on tetraplegic hand function. Clinical Results, Spinal Cord 40(11) (2002), 560-566.

[78] S. Davis, M. Mulcahey, S. BT and B. RR, Self-reported use of an implanted FES hand system by adolescents with tetraplegia, Journal of Spinal Cord Medicine 21(3) (1998), 220-226.

[79] S.E. Davis, M.J. Mulcahey, R.R. Betz, B.T. Smith and A.A. Weiss, Outcomes of upper-extremity tendon transfers and functional electrical stimulation in an adolescent with C5 tetraplegia, American Journal of Occupational Therapy 51(4) (1997), 307-312.

[80] G. Alon and K. McBride, Persons with C5 or C6 tetraplegia achieve selected functional gains using a neuroprosthesis, Archives of Physical Medicine and Rehabilitation 84(1) (2003), 119-124.

[81] B.R. Seeger, D. Law, J.E. Creswell, L.M. Stern and G. Potter, Functional Electrical-Stimulation For Upper Limb Strengthening In Traumatic Quadriplegia, Archives of Physical Medicine and Rehabilitation 70(9) (1989), 663-667.

[82] B.M. Needham-Shropshire, J.G. Broton, T.L. Cameron and K.J. Klose, Improved motor function in tetraplegics following neuromuscular stimulation-assisted arm ergometry, $J$ Spinal Cord Med 20(1) (1997), 49-55.

[83] A.I.F. Spooren, Y.J.M. Janssen-Potten, E. Kerckhofs and H.A.M. Seelen, Outcome Of Motor Training Programmes On Arm And Hand Functioning In Patients With Cervical Spinal Cord Injury According To Different Levels Of The Icf: A Systematic Review, Journal of Rehabilitation Medicine 41(7) (2009), 497-505.

[84] J.A. Davis, R.J. Triolo, J.P. Uhlir, N. Bhadra, D.A. Lissy, S. Nandurkar and E.B. Marsolais, Surgical technique for installing an eight-channel neuroprosthesis for standing, Clinical Orthopaedics and Related Research (385) (2001), 237252.

[85] R.J. Triolo, C. Bieri, J. Uhlir, R. Kobetic, A. Scheiner and E.B. Marsolais, Implanted functional neuromuscular stimulation systems for individuals with cervical spinal cord injuries: Clinical case reports, Archives of Physical Medicine and Rehabilitation 77(11) (1996), 1119-1128.

[86] R. Kobetic, C.S. To, J.R. Schnellenberger, M.L. Audu, T.C. Bulea, R. Gaudio, G. Pinault, S. Tashman and S. Triolo, Development of hybrid orthosis for standing, walking, and stair climbing after spinal cord injury, Journal of Rehabilitation Research and Development 46(3) (2009), 447-462.

[87] E.B. Marsolais and R. Kobetic, Functional-Aspects of Paraplegic Walking Using Electrical-Stimulation, Archives of Physical Medicine and Rehabilitation 66(8) (1985), 554554.

[88] E.B. Marsolais, R. Kobetic, H.J. Chizeck and J.L. Jacobs, Current status of walking orthosis for thoracic paraplegics, Neurorehabilation and Neural Repair 5 (1991), 13-22.

[89] J.L. Maxwell, M.H. Granat, G. Baardman and H.J. Hermens, Demand for and use of functional electrical stimulation systems and conventional orthoses in the spinal lesioned community of the UK, Artificial Organs 23(5) (1999), 410-412.

[90] R. D'Ambrosia, M. Solomonow and R. Baratta, Current status of walking orthosis for thoracic paraplegics, Iowa Orthopaedic Journal 15(174-181) (1995). 
[91] E.C. Field-Fote and D. Tepavac, Improved intralimb coordination in people with incomplete spinal cord injury following training with body weight support and electrical stimulation, Physical Therapy 82(7) (2002), 707-715.

[92] M. Solomonow, R. Baratta, S. Hirokawa, N. Rightor, W. Walker, P. Beaudette, H. Shoji and R. Dambrosia, The RGO Generation-II - Muscle Stimulation Powered Orthosis As A Practical Walking System For Thoracic Paraplegics, Orthopedics 12(10) (1989), 1309-1315.

[93] A. Nene and S. Jennings, Hybrid paraplegia locomotion with the ParaWalker using intramuscular stimulation: A single subjects study, Paraplegia 27 (1989), 125-132.

[94] R. Spadone, G. Merati, E. Bertocchi, E. Mevio, A. Veicsteinas, A. Pedotti and M. Ferrarin, Energy consumption of locomotion with orthosis versus Parastep-assisted gait: a single case study, Spinal Cord 41(2) (2003), 97-104.

[95] G. Merati, P. Sarchi, M. Ferrarin, A. Pedotti and A. Veicsteinas, Paraplegic adaptation to assisted-walking: energy expenditure during wheelchair versus orthosis use, Spinal Cord 38(1) (2000), 37-44

[96] M. Goldfarb, K. Korkowski, B. Harrold and W. Durfee, Preliminary evaluation of a controlled-brake orthosis for FESaided gait, Ieee Transactions on Neural Systems and Rehabilitation Engineering 11(3) (2003), 241-248.

[97] N.J. Postans, J.P. Hasler, M.H. Granat and D.J. Maxwell, Functional electric stimulation to augment partial weightbearing supported treadmill training for patients with acute incomplete spinal cord injury: A pilot study, Archives of Physical Medicine and Rehabilitation 85(4) (2004), 604 610.

[98] D.J. Gater, Spinal Cord Injury, in: Clinical Exercise Physiology, (2nd ed.), J. Ehrman, P. Gordon, P. Visich and S. Keteyian, eds, Champaign, IL: Human Kinetics, 2009, pp. 523-542.

[99] D. Gater, Exercise and Fitness with Spinal Cord Injury, in: Spinal Cord Injuries: Management and Rehabilitation, S. Sisto, E. Druin, M. Sliwinski, eds, St. Louis, MO: Mosby Elsevier, 2009, pp. 430-454.

[100] M.A. Nash and D.R. Gater, Exercise to Reduce Obesity in Spinal Cord Injury, Topics in Spinal Cord Injury Rehabiliation 12(4) (2007), 76-93.

[101] C.A. Phillips, Medical criteria for active physical therapy. physician guidelines for patient participation in a program of functional electrical rehabilitation, American Journal of Physical Medicine 66(5) (1987), 269-286.

[102] P.D. Faghri, R.M. Glaser, S.F. Figoni, D.S. Miles and S.C. Gupta, Feasibility of using two FNS exercise modes for spinal cord injured patients, Clinical Kinesiology 43(3) (1989), 6268.

[103] K.T. Ragnarsson, Physiologic effects of functional electrical stimulation-induced exercises in spinal cord injured individuals, Clinical Orthopaedics and Related Research 233 (1988), 53-63.

[104] M.M. Rodgers, R.M. Glaser, S.F. Figoni, S.P. Hooker, B.N. Ezenwa, S.R. collins, T. Mathews, A.G. Suryaprasad and S.C. Gupta, Musculoskeletal responses of spinal cord injured individuals to functional neuromuscular stimulation-induced knee extension exercise training, J Rehabil ResDev 28(4) (1991), 19-26.

[105] S.P. Hooker, S.F. Figoni, M.M. Rodgers, R.M. Glaser, T Mathews, A.G. Suryaprasad and S.C. Gupta, Physiologic effects of electrical stimulation leg cycle exercise training in spinal cord injured persons, ArchPhysMedRehabil 73(5) (1992), 470-476.
[106] S.F. Figoni, M.M. Rodgers, R.M. Glaser, S.P. Hooker, P.D. Feghri, B.N. Ezenwa, T. Mathews, A.G. Suryaprasad and S.C. Gupta, Physiologic responses of paraplegics and quadriplegics to passive and active leg cycle ergometry, J Am Paraplegia Soc 13(3) (1990), 33-39.

[107] N. Hjeltnes, D. Galuska, M. Bjornholm, A.K. Aksnes, A. Lannem, J.R. Zierath and J.R. Wallberg-Henriksson, Exercise-induced overexpression of key regulatory proteins involved in glucose uptake and metabolism in tetraplegic persons: molecular mechanism for improved glucose homeostasis, FASEB J 12(15) (1998), 1701-1712.

[108] P.B. Arnold, P.P. McVey, W.J. Farrell, T.M. Deurloo and A. Grasso, Functional electric stimulation:its efficacy and safety in improving pulmonary function and musculoskeletal fitness, Archives of Physical Medicine and Rehabiliatation 73(7) (1992), 665-668.

[109] T.J. Barstow, A.M. Scremin, D.L. Mutton, C.F. Kunkel, T.G. Cagle and B.J. Whipp, Changes in gas exchange kinetics with training in patients with spinal cord injury, Medicine and Science in Sports and Exercise 28(10) (1996), 1221-1228.

[110] M.S. Nash, M. Bilsker, H.M. Kearney, J.N. Ramirez, B. Applegate and B.A. Green, Effects of electrically-stimulated exercise and passive motion on echocardiographically-dericed wall motion and cardiodynamic function in tetraplegic persons, Paraplegia 33(2) (1995), 80-89.

[111] S.P. Hooker, S.F. Sigoni, M.M. Rodgers, R.M. Glaser, T. Matthews, A.G. Suryaprasad and A.G. Gupta, Metabolic and hemodynamic responses to concurrent voluntary arm crank and electrical stimulation leg cycle exercise in quadriplegics, Journal of Rehabilitation Research and Development 29(3) (1992), 1-11.

[112] W.A. Bauman, L.R. Alexander, Y.G. Zhong and A.M. Spungen, Stimulated leg ergometry training improves body composition and HDL-cholesterol values, Journal of the American Paraplegia Society 17(4) (1994), 201.

[113] S.A. Bloomfield, W.J. Mysiw and R.D. Jackson, Bone mass and endocrine adaptations to training in spinal cord injured individuals, Bone 19(1) (1996), 61-68.

[114] T.N. Hangartner, M.M. Rodgers, R.M. Glaser and P.S. Barre, Tibial bone density loss in spinal cord injured patients: effects of FES exercise, J Rehabil ResDev 31(1) (1994), 50-61.

[115] S.C. Chen, C.H. Lai, W.P. Chan, M.H. Huang, H.W. Tsai and J.J.J. Chen, Increases in bone mineral density after functional electrical stimulation cycling exercises in spinal cord injured patients, Disability and Rehabilitation 27(22) (2005), 13371341.

[116] D.E. Garland, C.A. Stewart, R.H. Adkins, S.S. Hu, C. Rosen, F.J. Liotta and D.A. Weinstein, Osteoporosis after spinal cord injury, J OrthopRes 10(3) (1992), 371-378.

[117] T. Mohr, J. Podenphant, F. BieringSorensen, H. Galbo, G. Thamsborg and M. Kjaer, Increased bone mineral density after prolonged electrically induced cycle training of paralyzed limbs in spinal cord injured man, Calcified Tissue International 61(1) (1997), 22-25.

[118] E.M. Leeds, K.J. Klose, W. Ganz, A. Serafini and B.A. Green, Bone-Mineral Density After Bicycle Ergometry Training, Archives of Physical Medicine and Rehabilitation 71(3) (1990), 207-209.

[119] B.M. NeedhamShropshire, J.G. Broton, K.J. Klose, N. Lebwohl, R.S. Guest and P.L. Jacobs, Evaluation of a training program for persons with SCI paraplegia using the Parastep(R)1 ambulation system .3. Lack of effect on bone mineral density, Archives of Physical Medicine and Rehabilitation 78(8) (1997), 799-803. 
[120] K.K. BeDell, A.M. Scremin, K.L. Perell and C.F. Kunkel, Effects of functional electrical stimulation-induced lower extremity cycling on bone density of spinal cord-injured patients, Am J PhysMedRehabil 75(1) (1996), 29-34.

[121] K.D. Anderson, Targeting recovery: Priorities of the spinal cord-injured population, Journal of Neurotrauma 21(10) (2004), 1371-1383.

[122] G.S. Brindley, C.E. Polkey and D.N. Rushton, Sacral Anterior Root Stimulators for Bladder Control in Paraplegia, Paraplegia 20(6) (1982), 365-381.

[123] G.S. Brindley, The First 500 Patients with Sacral Anterior Root Stimulator Implants - General Description, Paraplegia 32(12) (1994), 795-805.

[124] N. Bhadra, V. Grunewald, G.H. Creasey and J.T. Mortimer, Selective activation of the sacral anterior roots for induction of bladder voiding, Neurourology and Urodynamics 25(2) (2006), 185-193.

[125] G.H. Creasey, J.H. Grill, M. Korsten, H. Sang, R. Betz, R. Anderson and J. Walter, Implanted Neuroprosthesis Res G: An implantable neuroprosthesis for restoring bladder and bowel control to patients with spinal cord injuries: A multicenter trial, Archives of Physical Medicine and Rehabilitation 82(11) (2001), 1512-1519.

[126] G.S. Brindley, The First 500 Sacral Anterior Root Stimulators - Implant Failures and Their Repair, Paraplegia 33(1) (1995), 5-9.

[127] J.G. Banwell, G.H. Creasey, A.M. Aggarwal and J.T. Mortimer, Management of the Neurogenic Bowel In Patients With Spinal Cord Injury, Urologic Clinics of North America 20(3) (1993), 517-526.

[128] N.R. Binnie, A.N. Smith, G.H. Creasey and P. Edmond, Con- stipation Associated With Chronic Spinal Cord Injury - The Effect of Pelvic Parasympathetic Stimulation by the Brindley Stimulator, Paraplegia 29(7) (1991), 463-469.

[129] T.E. Johnston, R.R. Betz, B.T. Smith, B.J. Benda, M.J. Mulcahey, R. Davis, T.P. Houdayer, M.A. Pontari, A. Barriskill and G.H. Creasey, Implantable FES system for upright mobility and bladder and bowel function for individuals with spinal cord injury, Spinal Cord 43(12) (2005), 713-723.

[130] M. Valles, A. Rodriguez, A. Borau and F. Mearin, Effect of Sacral Anterior Root Stimulator on Bowel Dysfunction in Patients with Spinal Cord Injury, Diseases of the Colon and Rectum 52(5) (2009), 986-992.

[131] G.S. Brindley, Neuroprostheses Used to Restore Male Sexual or Reproductive Function, Baillieres Clinical Neurology 4(1) (1995), 15-20.

[132] N.L. Brackett, C.M. Lynne, E. Ibrahim, D.A. Ohl and D.A. Sonksen, Treatment of infertility in men with spinal cord injury, Nature Reviews Urology 7(3) (2010), 162-172.

[133] J. Sonksen and D.A. Ohl, Penile vibratory stimulation and electroejaculation in the treatment of ejaculatory dysfunction, International Journal of Andrology 25(6) (2002), 324-332.

[134] J. Sonksen and D.A. Ohl, Assisted ejaculation, International Journal of Andrology 28 (2005), 18-18.

[135] T. Sramkova, M. Sutory and P. Travnik, Electroejaculation and assisted reproductive techniques in men with spinal cord injury, Journal of Sex Research 45(2) (2008), 111-111.

[136] J.S. French, K.D. Anderson-Erisman and M. Sutter, What do Spinal Cord Injury Consumers Want? A Review of Spinal Cord Injury Consumer Priorities and Neuroprosthesis from the 2008 Neural Interfaces Conference, Neuromodulation 13(3) (2010), 229-231. 